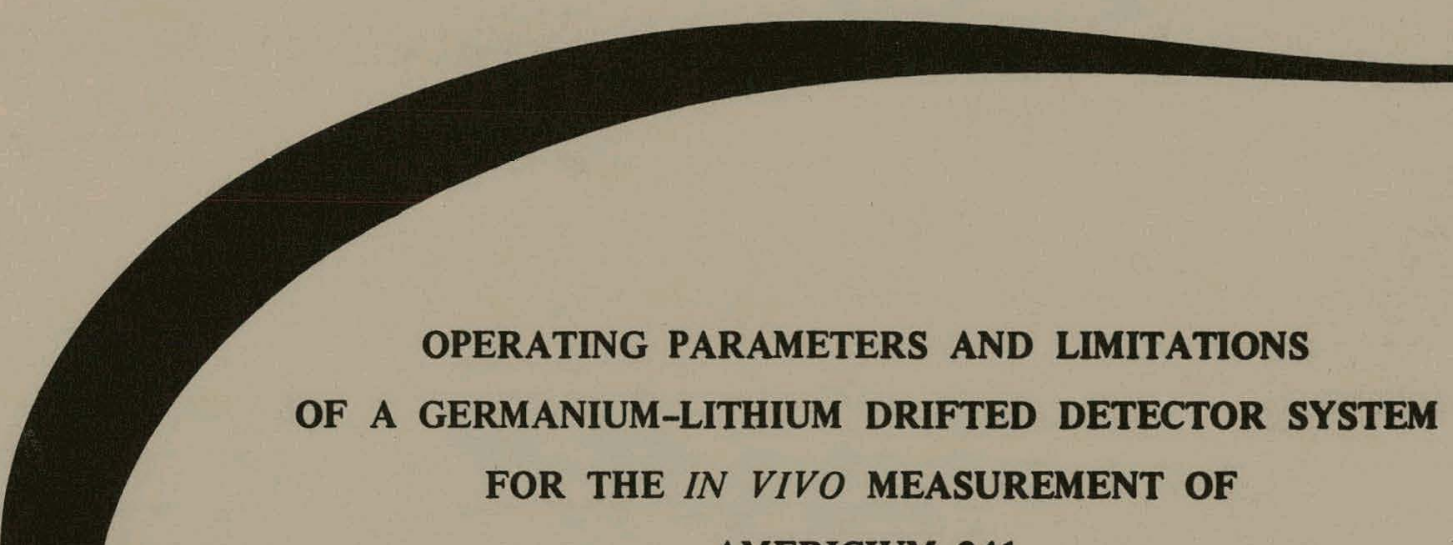

AMERICIUM-241

William H. Tyree

Roger B. Falk

Ronald W. Liskey

Charles B. Wood

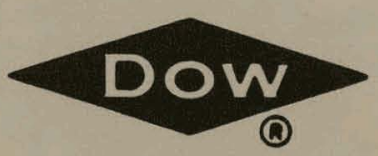

DOW CHEMICAL U.S.A. ROCKY FLATS DIVISION P. O. BO 888 GOLDEN, COLORADO 80401

U. S. ENERGY RESEARCH AND DEVELOPMENT ADMINISTRATION CONTRACT AT(29-1)-1106 


\section{DISCLAIMER}

This report was prepared as an account of work sponsored by an agency of the United States Government. Neither the United States Government nor any agency Thereof, nor any of their employees, makes any warranty, express or implied, or assumes any legal liability or responsibility for the accuracy, completeness, or usefulness of any information, apparatus, product, or process disclosed, or represents that its use would not infringe privately owned rights. Reference herein to any specific commercial product, process, or service by trade name, trademark, manufacturer, or otherwise does not necessarily constitute or imply its endorsement, recommendation, or favoring by the United States Government or any agency thereof. The views and opinions of authors expressed herein do not necessarily state or reflect those of the United States Government or any agency thereof. 


\section{DISCLAIMER}

Portions of this document may be illegible in electronic image products. Images are produced from the best available original document. 


\section{LEGAL NOTICE}

This report was prepared as an account of work sponsored by the United States Government. Neither the United States nor the United States Atomic Energy Commission, nor any of their employees, nor any of their contractors, subcontractors, or their employees, makes any warranty, expressed or implied, or assumes any legal liability or responsibility for the accuracy, completeness or usefulness of any information, apparatus, product or process disclosed, or represents that its use would not infringe privately owned rights.

Printed in the United States of America

Available from the

National Technical Information Service

U. S. Department of Commerce

Springfield, Virginia 22151

Price: Printed Copy $\$ 4.00$ Microfiche $\$ 2.25$ 
Printed

February 3, 1975
RFP-2328

UC-4 1 HEALTH AND SAFETY

TID-4500-R62

\section{OPERATING PARAMETERS AND LIMITATIONS \\ OF A GERMANIUM-LITHIUM DRIFTED DETECTOR SYSTEM \\ FOR THE IN VIVO MEASUREMENT OF}

AMERICIUM-241

Health Sciences

RADIATION INSTRUMENTATION GROUP

William H. Tyree

RADIATION DOSIMETRY GROUP

Roger B. Falk

Ronald W. Liskey

Charles B. Wood

This report was prepared as an account of work
sponsored by the United States Government. Neither
the United States nor the United States Energy
Research and Development Administration, nor any of
their employees, nor any of their mntrartinrs,
subcontractors, or their employees, makes any
warranty, express or implied, or assumes any legal
liability or responsibility for the accuracy, completeness
or usefulness of any information, apparatus, product or
process disclosed, or represents that its use would not
infringe privately owned rights.

\section{SUBJECT DESCRIPTORS}

Body Counter

Germanium-Lithium Drifted Detector Germanium Detector Plutonium-239

Americium

DOW CHEMICAL U.S.A.

ROCKY FLATS DIVISION

P. O. BOX 888

GOLDEN, COLORADO 80401

Prepared under Contract AT(29-1)-1106

for the

Albuquerque Operations Office

U.S. Energy Research and Development Administration

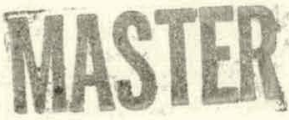




\section{CONTENTS}

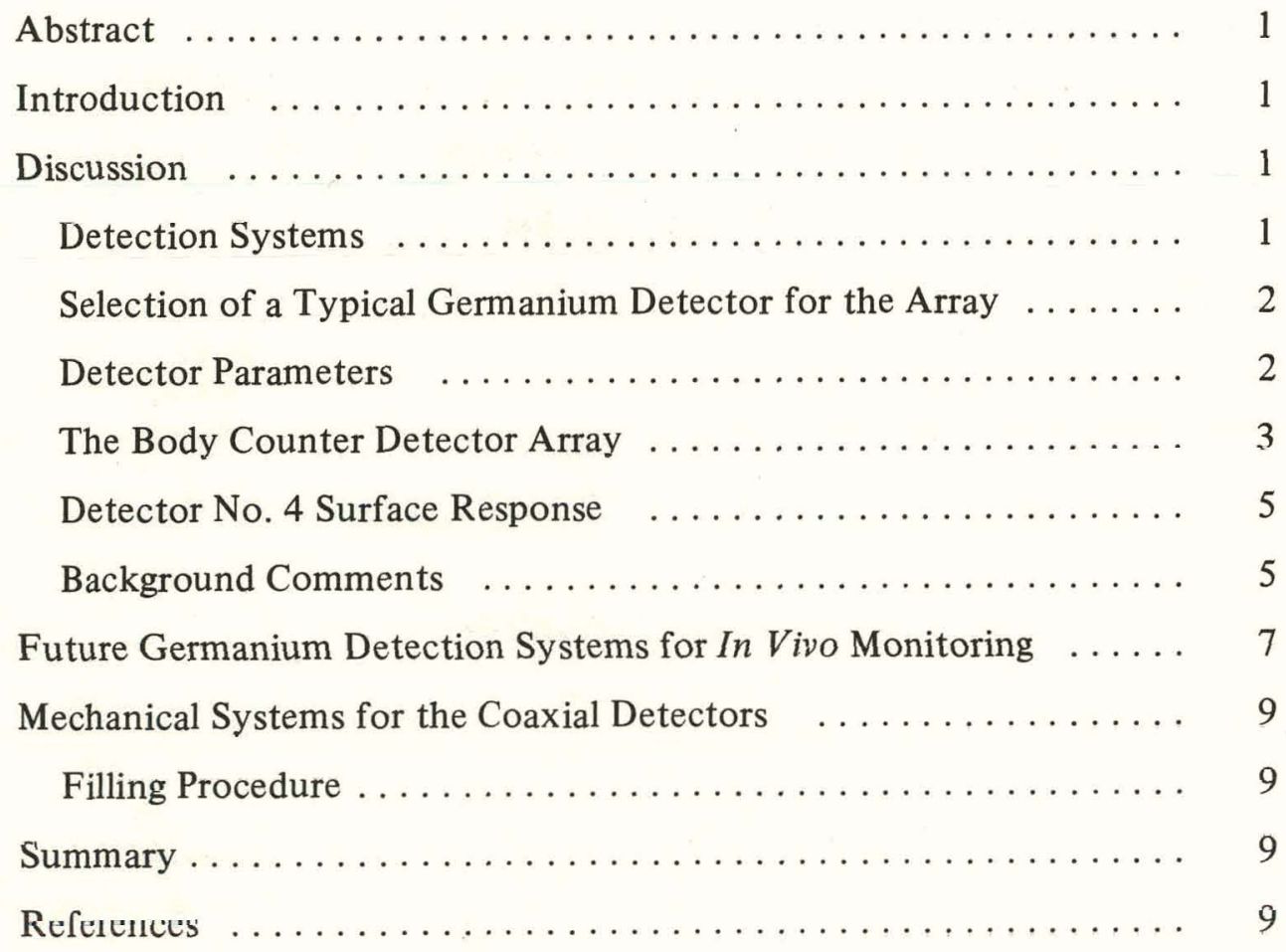




\title{
OPERATING PARAMETERS AND LIMITATIONS OF A GERMANIUM-LITHIUM \\ DRIFTED DETECTOR SYSTEM FOR THE IN VIVO \\ MEASUREMENT OF AMERICIUM-241
}

\author{
William H. Tyree, Roger B. Falk, Ronald W. Liskey, and Charles B. Wood
}

\begin{abstract}
The body counter facility at the Rocky Flats Plant provides for the detection of americium241 , as a tracer for plutonium, which is present in some plutonium mixtures. A germanium-lithium drifted system is described in this report and application for the in vivo measurement of americium-241 is discussed. The operating parameters and limitations of the germanium-lithium drifted system for low-energy photon detection with particular attention to the entrance window response of one of the detectors are presented. Future development of germanium systems for the detection of low-energy photons in vivo will use hyper-pure germanium fabricated as thinwindow planar detectors.
\end{abstract}

\section{INTRODUCTION}

The body counter at the Rocky Flats Plant is used for the detection and measurement of low-level amounts of plutonium and americium, which may be deposited in the lungs of personnel exposed to plutonium mixtures. The method involves the use of americium-241, as a tracer for plutonium, which is present in plutonium mixtures as the daughter product of plutonium-241. The method is based on the measurement of the 59.5kiloelectron volt $(\mathrm{keV})$ gamma emitted from the decay of americium-241.

A system of germanium-lithium drifted [ $\mathrm{Ge}(\mathrm{Li})]$ detectors was developed in an attempt to improve the sensitivity of the measurement, so that smaller and smaller amounts of the americium-241 could be measured accurately. This report will review the operating parameters and limitations of a coaxial $\mathrm{Ge}(\mathrm{Li})$ system for the measurement of americium in the lungs with particular attention to the specific characteristics of one of these detectors.

\section{DISCUSSION}

\section{Detection Systems:}

The current detection system consists of two single-crystal scintillation detectors. The detector crystal is thallium-activated sodium iodide, $\mathrm{NaI}(\mathrm{Tl})$, with a thickness of 4 millimetres $(\mathrm{mm})$ and a surface area of 81 square centimetres $\left(\mathrm{cm}^{2}\right)$ per detector. The system is noteworthy for its large surface area, stable operation, and virtually 100 percent efficiency at the $59.5-\mathrm{keV}$ photon energy of americium-241 ( $\left.{ }^{241} \mathrm{Am}\right)$.

The Ge(Li) coaxial detectors, which were investigated, each had a surface area of 15 to $16 \mathrm{~cm}^{2}$ and a volume of approximately 40 cubic centimetres $\left(\mathrm{cm}^{3}\right)$. The surface of the detector is covered by a thin layer of inactive (dead) germanium which absorbs low energy photons so that few photons with energies less than $40 \mathrm{keV}$ are able to penetrate to the active part of the detector and be detected.

The advantage of the $\mathrm{Ge}(\mathrm{Li})$ detector is the excellent resolution over that compared to the $\mathrm{NaI}(\mathrm{Tl})$ detector. This feature is illustrated in Figure 1 which shows a typical spectrum of ${ }^{241} \mathrm{Am}$ for each type of detector (not drawn to comparable scale). A resolution of $0.9 \mathrm{keV}$ at full-width-halfmaximum (FWHM) for the $\mathrm{Ge}(\mathrm{Li})$ detector compared to $25 \mathrm{keV} \mathrm{FWHM}$ for the NaI(Tl) detector means that the summation of the counts in the $59.5 \mathrm{keV}$ peak can occur over a much smaller portion of the background spectrum for the $\mathrm{Ge}(\mathrm{Li})$ detector. The lower background thus obtained would lead to the ability to distinguish smaller values of positive count for the same surface area, and hence to a better sensitivity. 


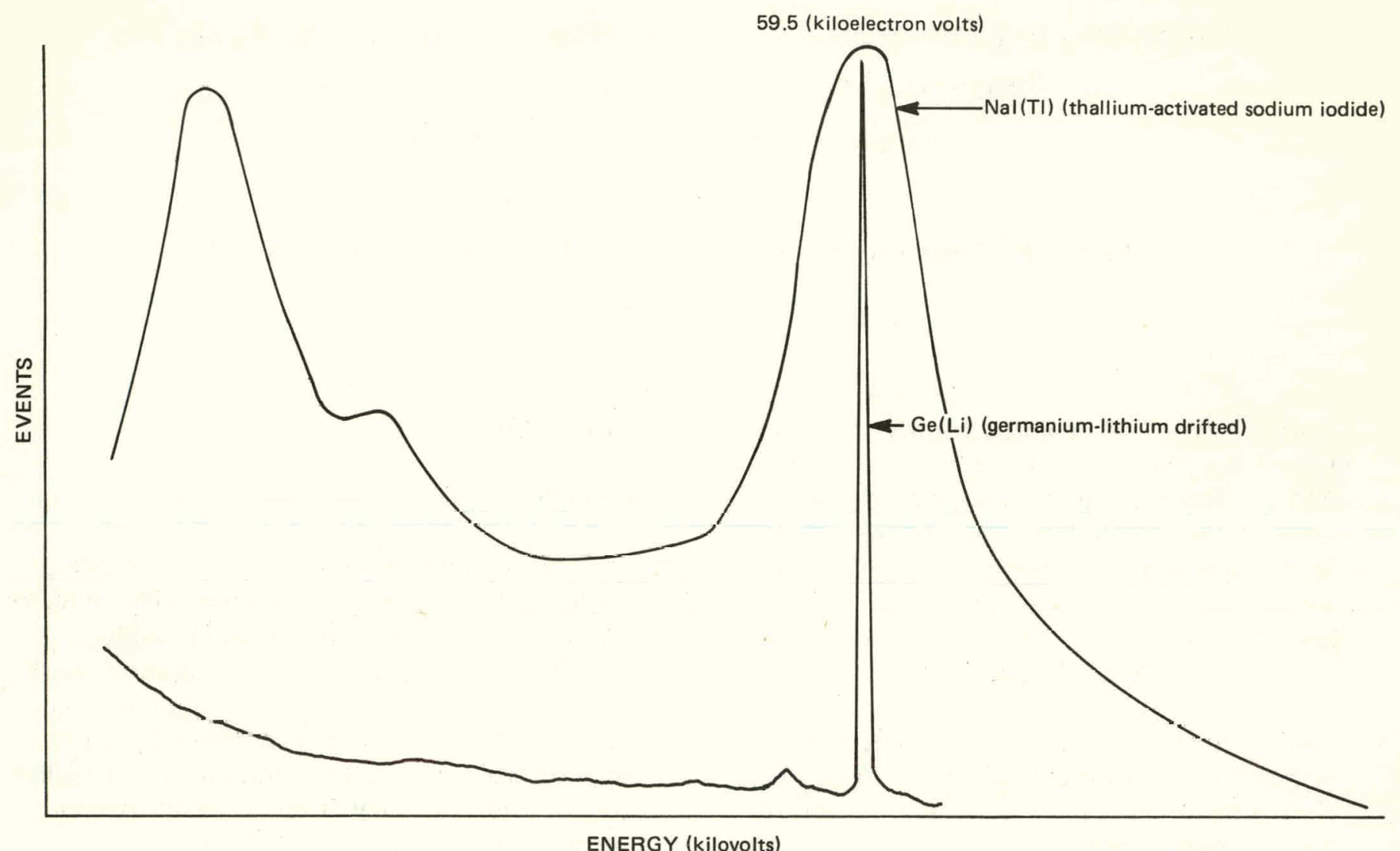

FIGURE 1. Resolution Comparison.

\section{Selection of a Typical Germanium Detector} for the Array:

At the time the specifications for the germanium array were being developed, the commercial manufacturers of these types of detectors indicated the availability of large planar detectors for lowenergy photon detection. By the time budgeting for these detectors had been established and the funds were made available, the commercial manufacturers had experienced considerable difficulty in building consistent planar detectors having the required surface area with lithiumdrifted technology. This situation led to the assumption that co-axial detectors would provide the optimum combination of surface area, resolution, and cost. The performance of this system, utilizing the coaxial detector configuration, is documented in the remainder of this report. Only one of the detectors is included in the detailed study of the performance, but preliminary results from measurements made on the other three detectors indicate that they have similar characteristics, although not to the same extent.

\section{Detector Parameters:}

Each of the four detectors is a coaxial, closed-end $\mathrm{Ge}(\mathrm{Li})$ detector with a physical surface area of 15 to $16 \mathrm{~cm}^{2}$ and a lithium-drifted depth of $28 \mathrm{~mm}$. The fourth detector is mounted in a horizontal aluminum cryostat with the P-center region of the detector mounted towards the entrance window. Figure 2 shows the idealized form. The N-region forms the closed sides of the detector. The edges of the interior active volume of the compensated intrinsic germanium are difficult to determine because of the loss of scattered photons out of th active volume. The same is true in the detector volume near the $\mathrm{P}$ core in the center of the detector. 


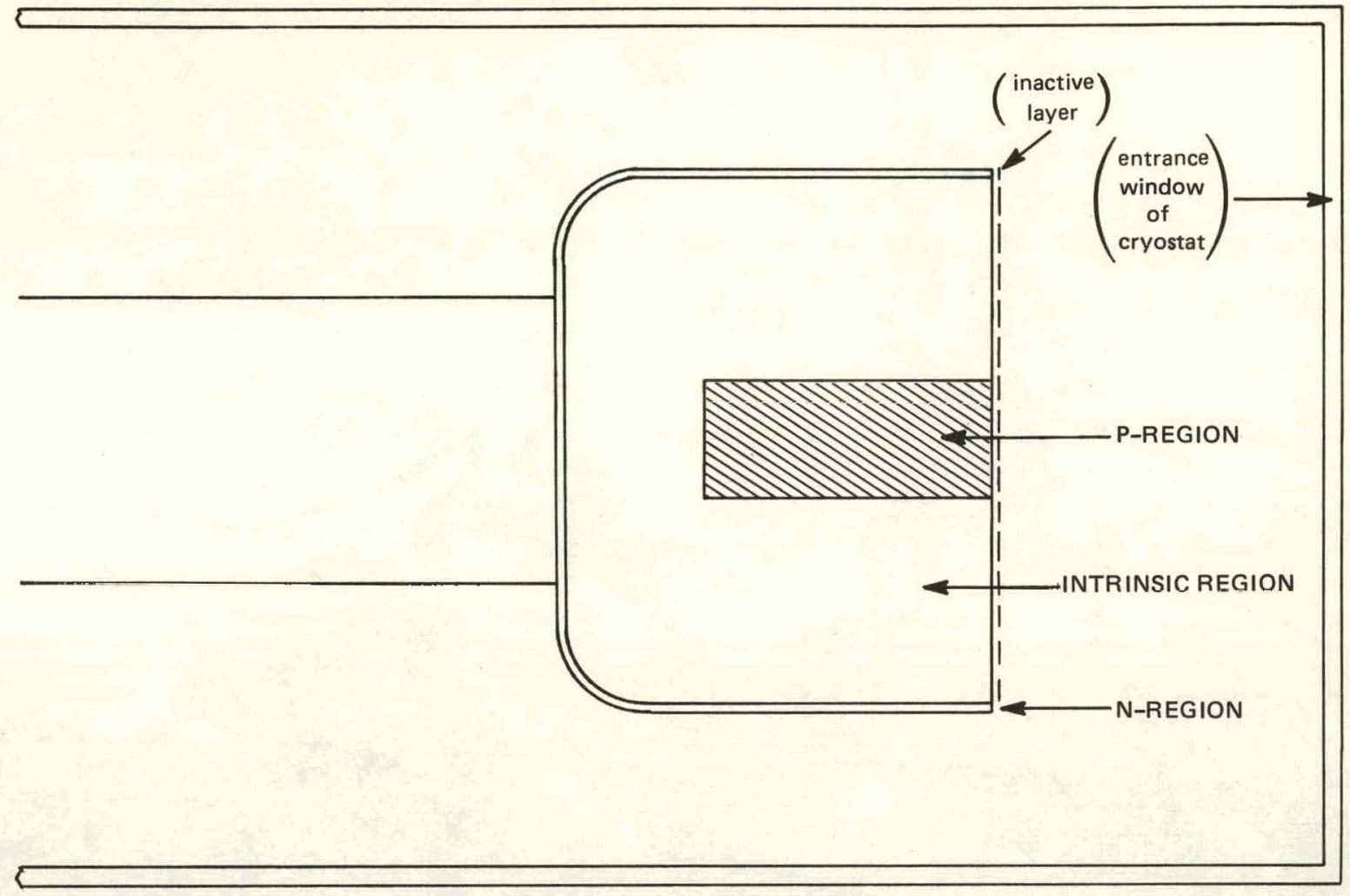

FIGURE 2. Expanded View of a Typical Coaxial Germanium-Lithium Drifted Detector.

A resolution of $0.9-\mathrm{keV}$ FWHM is obtained by having each detector operating with each preamplifier first stage field effect transistor (FET) mounted inside its cryostat and operated at cryogenic temperatures.

\section{The Body Counter Detector Array:}

In order to obtain a surface area comparable to that of a $\mathrm{NaI}(\mathrm{Tl})$ detector, an array of $\mathrm{Ge}(\mathrm{Li})$ was assembled. Current lithium-drifted detector technology does not recommend the placement of multiple detectors in a single cryostat. Separate cryostats were provided for each detector.

An array of six coaxial detectors, each with a surface area of 15 to $16 \mathrm{~cm}^{2}$, was assembled to provide a total detection surface area of 90 to $96 \mathrm{~cm}^{2}$. Because of mechanical interferences from the Dewar flasks and liquid nitrogen supply lines, arrangement of the system around a patient was cumbersome. The system was reduced to four detectors to provide easier positioning capability and to eliminate possible claustrophobic effects with some patients. This reduction, of course, reduced the detector area to 60 to $64 \mathrm{~cm}^{2}$. The interior of the counting chamber with the four detectors in position is shown in Figure 3.

Figure 4 shows the typical amplifying system used with each of the four detectors used in the array. The electronics system accepts the pulses obtained from four separate signals, and presents them to a common analog to digital converter (ADC) and mixer router. This provides for separate storage of the pulse data in dedicated portions of the analyzer memory. The data obtained from the 8000 -second data collection period are manipulated by software control from the computer-based data system.

The computer-based system is shown in Figure 5.

The detectors are specified to have a 95 percent absorption capability at the $122-\mathrm{keV}$ photon 
RFP-2328

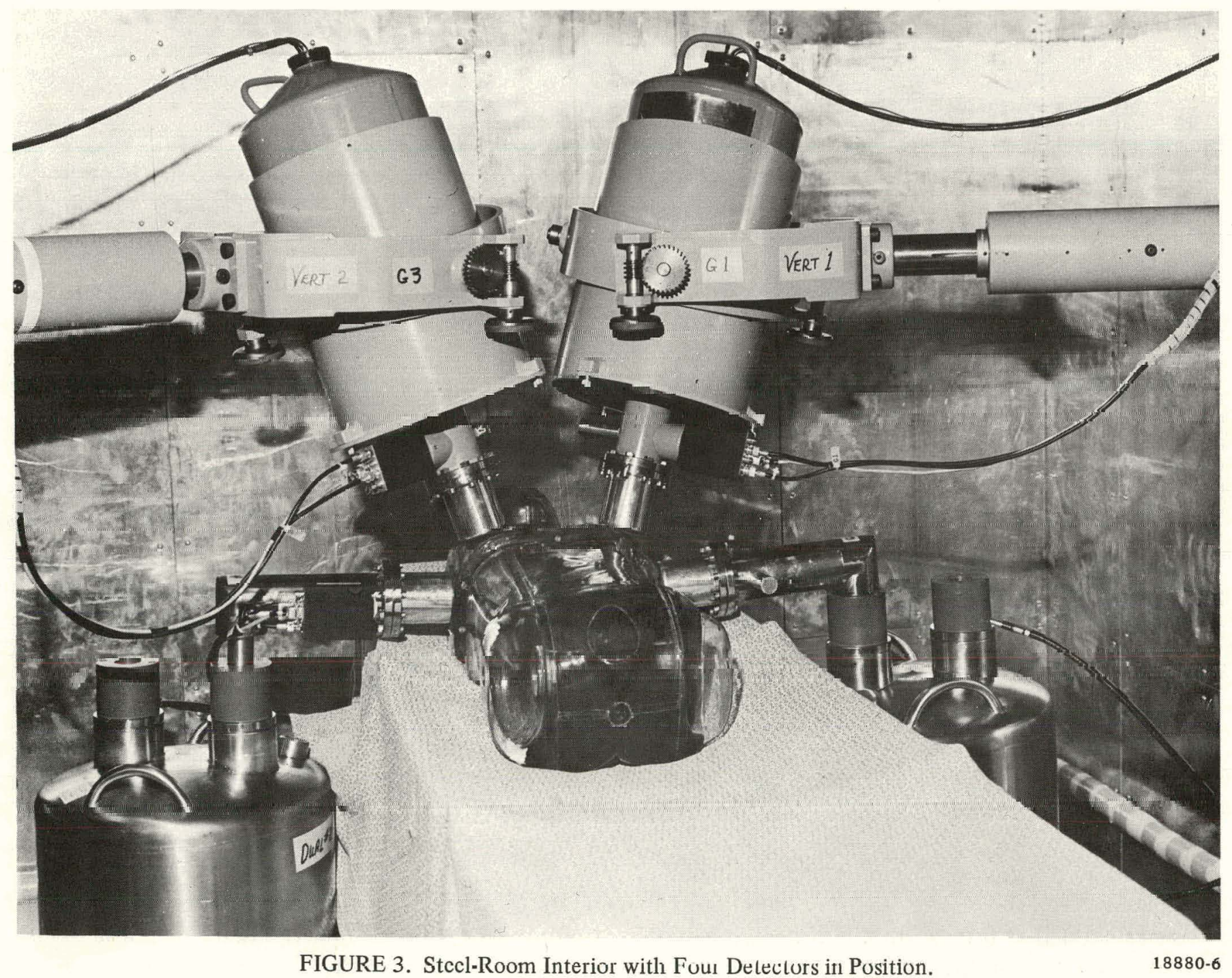




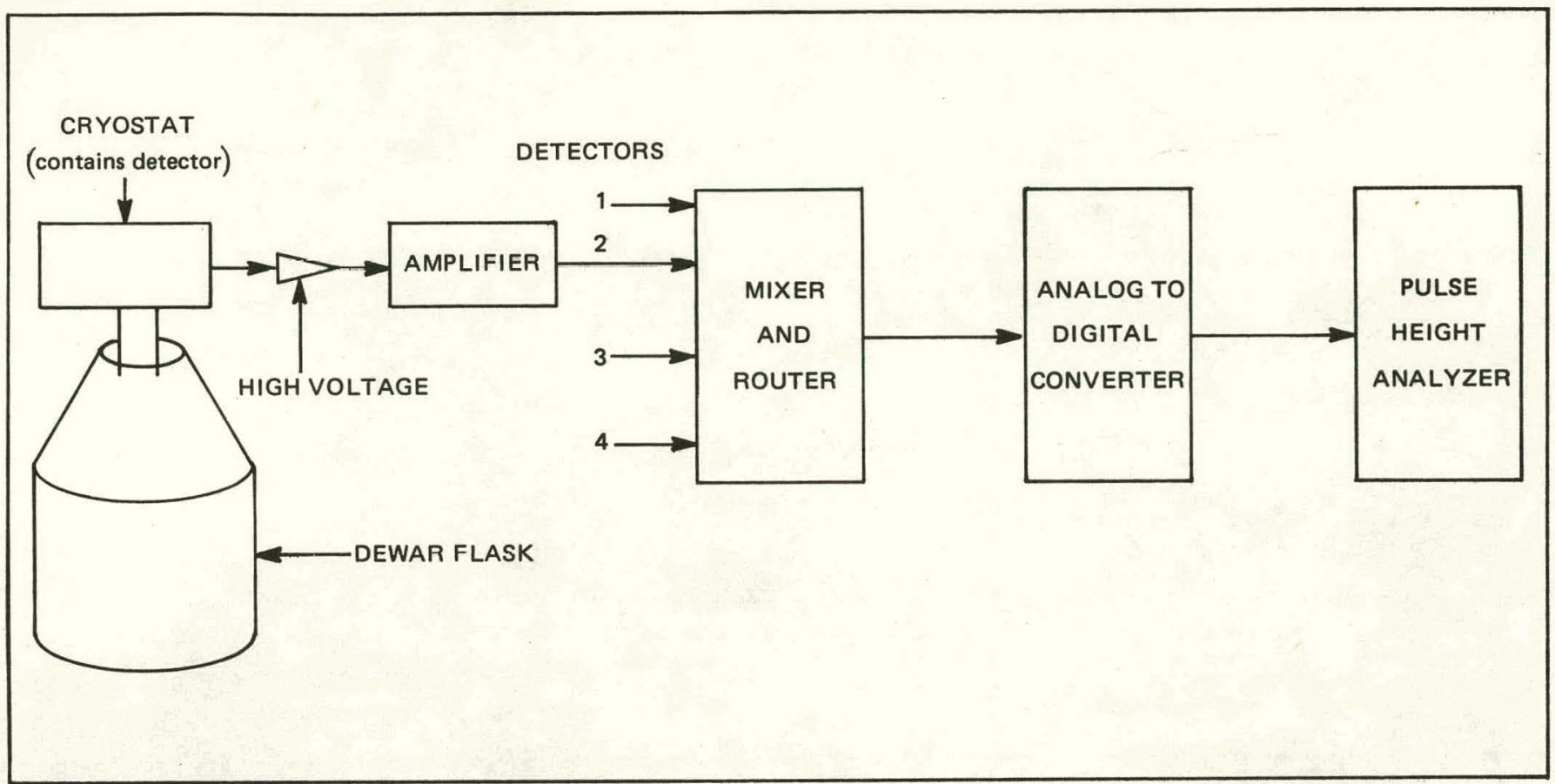

FIGURE 4. Germanium Detector System for Each of Four Detectors.

energy as measured for the gamma from cobalt- 57 . A uniform inactive layer over the surface of the detector was assumed. The layer produced a general response of $1: 1$ for the 81 to $31 \mathrm{keV}$ photons from an unshielded source of barium-133. It was also assumed that the active surface area of the detector corresponded to the detector surface area at any photon energy.

The energy calibration for the counting of ${ }^{241} \mathrm{Am}$ was set at $1.2 \mathrm{keV}$ per channel so that approximately 80 percent of the counts of the $59.5-\mathrm{keV}$ gamma from ${ }^{241} \mathrm{Am}$ would be accumulated in a single channel (Channel 42). Figure 6 shows the spectra obtained for each of the four detectors measuring ${ }^{241} \mathrm{Am}$ in simulated lungs in the lung cavity of a water-filled plastic phantom.

\section{Detector No. 4 Surface Response:}

The differences in responses of the detectors led to a review of the assumptions concerning the effective surface area of the detectors for measurement of the $59.5 \mathrm{keV}$ photons. The diameter of the detector was measured by positioning a collimated lead-shielded source across the width of the cryostat end cap on each side of center. Three sources were used to give the detector response for low, intermediate, and high energy photons. Figure 7 shows the relative response of Detector No. 4 to cesium-137 $(662 \mathrm{keV})$, cobalt-57 (122 keV), and americium$241(59.5 \mathrm{keV})$.

The results of the measurement indicated that the inactive attenuating layer on the surface of the detector is not uniform in thickness and that the effective surface area is a function of incident photon energy. For the $59.5-\mathrm{keV}$ photons from americium-241, the effective area was approximately 20 percent of the total assumed surface area for Detector No. 4.

\section{Background Comments:}

It should be noted that the detector background count per channel is a function of the total volume of the detector. Thus only the count from the 
RFP-2328

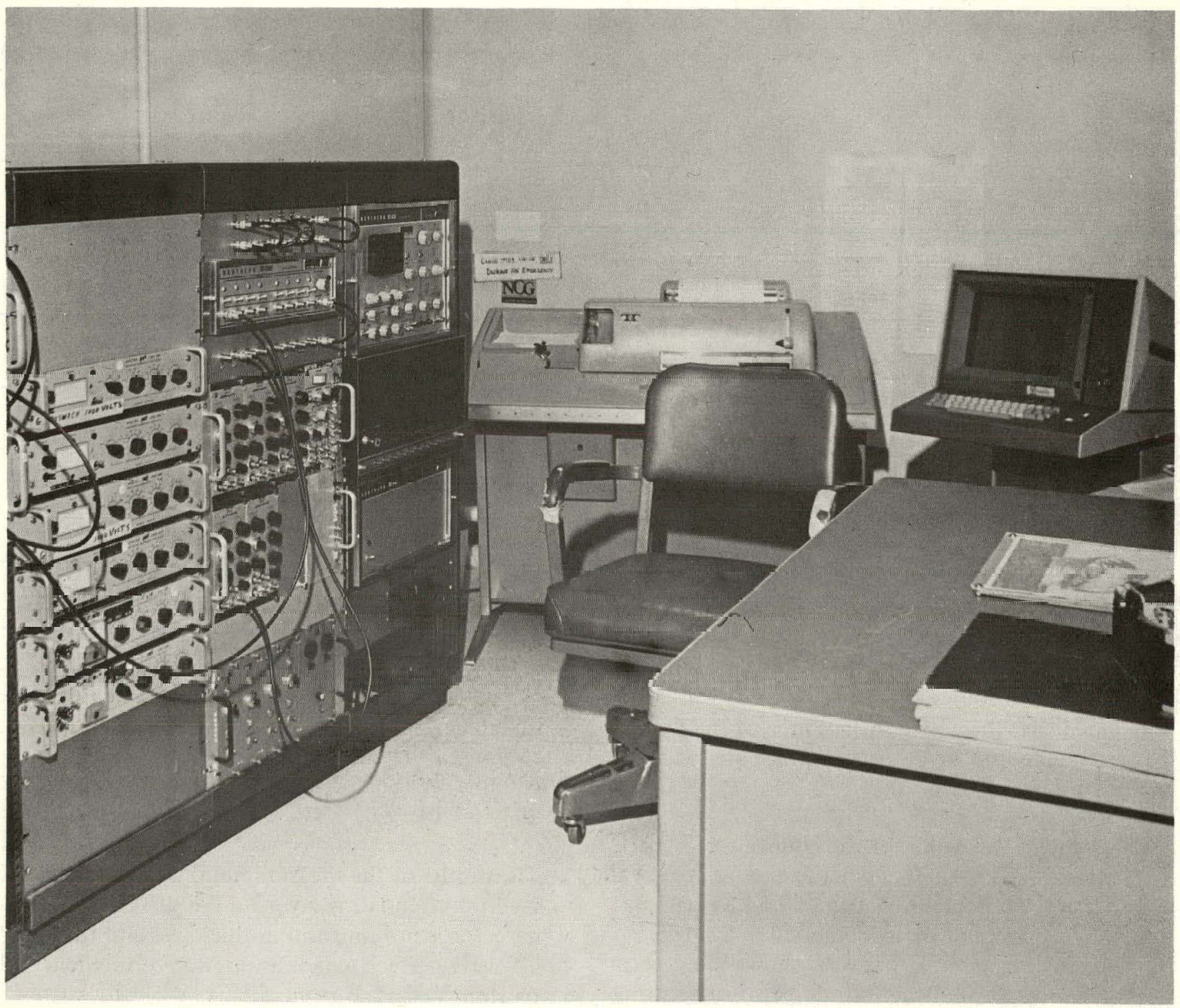

FIGURE 5. Computer-Based System. 
RFP-2328

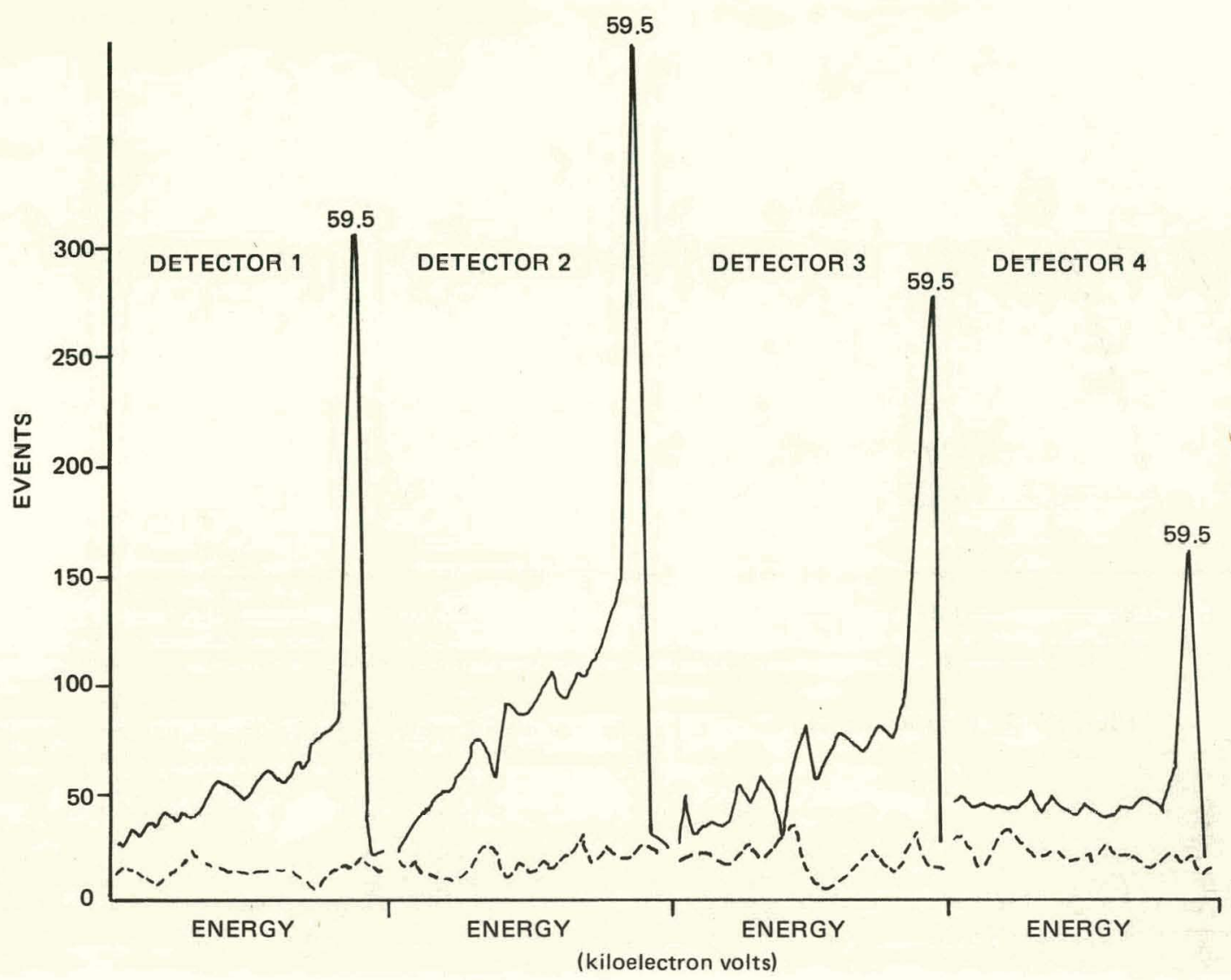

FIGURE 6. Responses from Four Detectors to Measure Photons in Phantom.

americium-241 is lost by the loss of effective surface area, while the background counting rate is not significantly effected. The advantage of obtaining excellent resolution from these coaxial detectors allows the lowering of background by placing the peak counts in a smaller portion of the background spectrum. However, the lack of a large, dependable, and effective surface area, and the effect of a significant fraction of the surface area accumulating only background counts limit the usefulness of the coaxial detection system for measurements of low-level quantities of americium241.

\section{FUTURE GERMANIUM DETECTION SYSTEMS FOR IN VIVO MONITORING}

Present 1974 germanium technology is now producing germanium ingots of sufficient purity to provide high resolution large-area planar detectors without lithium drifting. Since the detector performance is not dependent upon a lithiumcompensated region for psuedo-intrinsic operation, the detector is much more stable even at room temperature. The ability to maintain stable characteristics at room temperature means that an array of these detectors may be assembled much more easily into a single large cryostat. If maintenance is needed on one of the individual devices, the entire system may be brought to room temperature without endangering the other devices in the array.

This capability of using multiple detectors in a single cryostat will provide a detection system more comparable in area to the $\mathrm{NaI}(\mathrm{Tl})$ with the high resolution necessary to provide improved sensitivity for in vivo monitoring of americium-241 and plutonium-239. 
RFP-2328

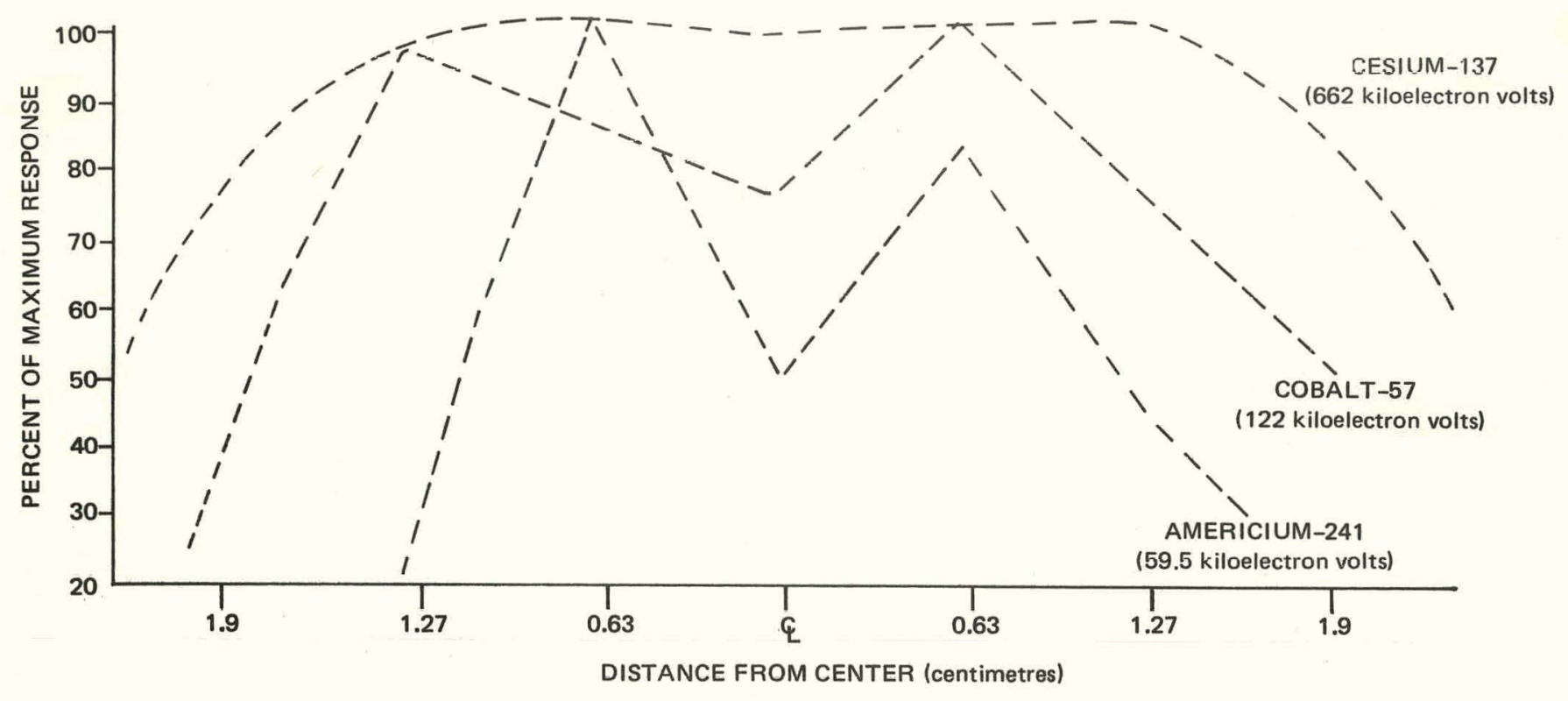

FIGURE 7. Relative Responses of Detector No. 4 (symmetry assumed at \pm 20 percent).

FIGURE 8. Valve System willı Huizuntal Cıyustat.

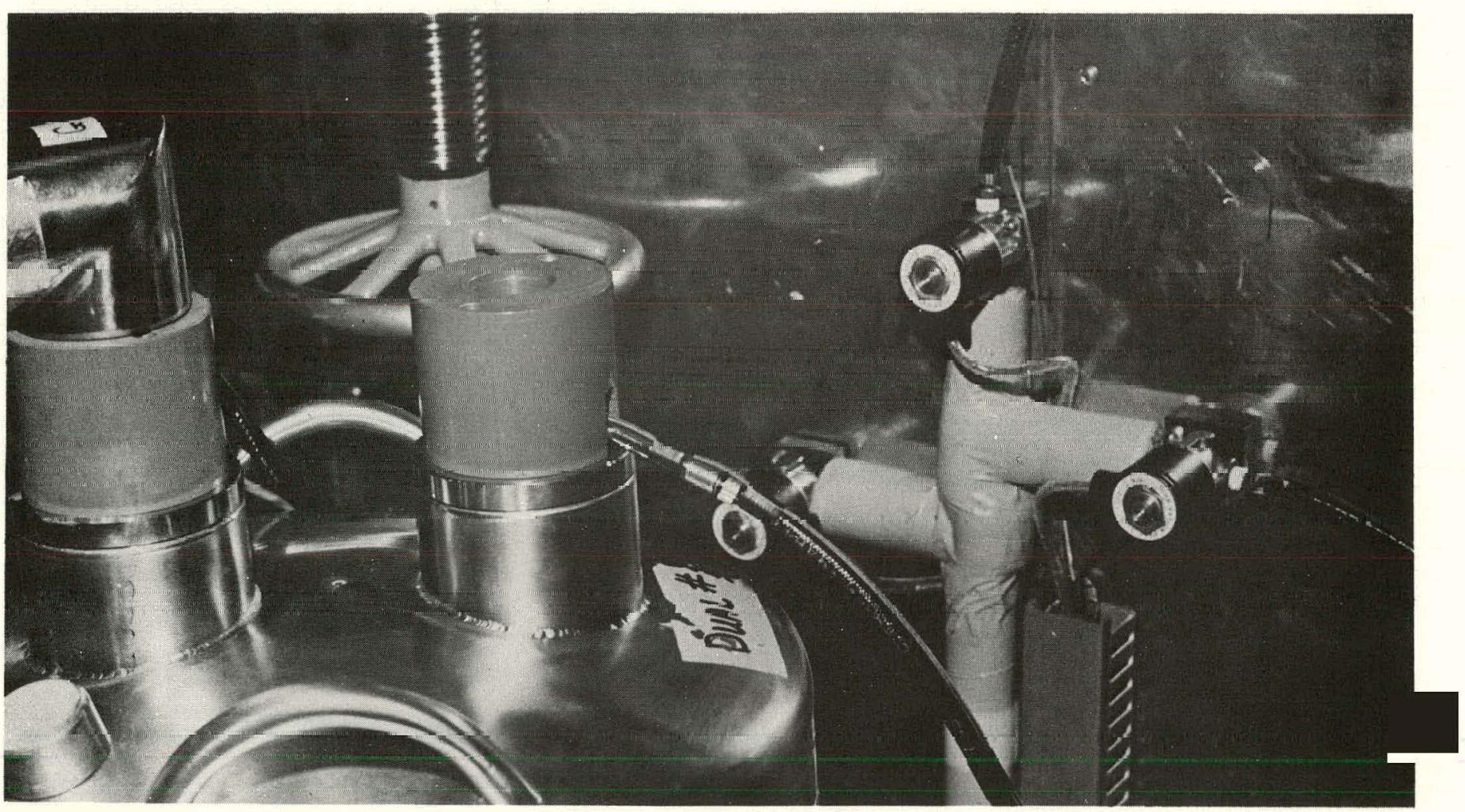




\section{MECHANICAL'SYSTEMS FOR} THE COAXIAL DETECTORS

The use of germanium, and particularly lithiumdrifted detectors, includes the requirement of providing liquid nitrogen at regular intervals to always insure that the detector Dewars are never allowed to go dry. A control system with cryogenic valving is included in the interior of the steel room to facilitate the filling of the Dewars. The control system provides lights for indicating the liquidlevel monitor temperature and therefore the filled condition of the Dewars. Filling of the Dewars is done by manual control to insure that the procedure cannot be initiated while anyone is inside the room. Figure 8 shows the valve system inside the room with one of the horizontal cryostats in a two-port Dewar.

\section{Filling Procedure:}

The sensing modules located in the bottom of the middle rack of the operating console provide visual indicators for power to the units and lights for indicating the liquid level in the Dewars. When filling is desired and all lights are illuminated, place all of the control switches in manual position. Before filling begins, the master control switch must be in the $O N$ position. The switches utilize detents to insure a positive switch position. The switch handle is pulled before moving to a new location.

\section{SUMMARY}

A germanium-lithium drifted detection system, with four large volume $\left(40 \mathrm{~cm}^{3}\right)$ coaxial detectors for application to the in vivo monitoring of americium-241, has been developed. Each detector in the array is capable of greater than 95 percent absorption for the $122 \mathrm{keV}$ photon of cobalt- 57 . Each detector has the first stage of the preamplifier mounted inside the cryostat, which helps producs a detector resolution of $0.9-\mathrm{keV}$ FWHM at $122 \mathrm{keV}$. This configuration provides the best resolution available for this type of detector, but requires factory rebuild if the FET is inadvertently destroyed in system operation.
The entrance window-surface area of these detectors has been determined to be dependent upon the energy of the incident photon. In the case of the fourth detector in the array, the entrance area for photons having an energy of $59.5 \mathrm{keV}$ was approximately 20 percent of that entrance area available for photons from cesium-137 (662 keV).

The lack of a consistent surface area for the entire range of photons, and the effect of most of the surface area providing only background counts limit the usefulness of this system for high sensitivity measurements of americium-241.

\section{REFERENCES}

1. G. A. Armantrout, A. E. Bradley, and P. L. Phelps. "Sensitivity Problems in Biological and Environmental Counting." Page 107. Transactions on Nuclear Science of the Institute of Electrical and Electronics Engineers, Volume NS-19. February 1972. Sympsoium held in San Francisco, California. November 3-5, 1971.

2. G. V. Walford, D. T. W. Aliaga-Kelly, and W. B. Gilboy. "The Direct Evaluation of Low Level Counting Techniques Employing Ge(Li) Detectors." Page 129. Transactions ....

3. R. H. Pehl, R. C. Cordi, and F. S. Goulding. "High Purity Germanium Detector Fabrication and Performance." Page 265. Transactions....

4. Z. H. Cho and R. L. Chase. "Improved Amplitude and Rise Time Compensated Timing with Ge Detectors." Page 451. Transactions....

5. William H. Tyree. Single Scintillation Crystal versus Phoswich.Detectors for In Vivo LowEnergy Photon Detection. RFP-2136. Rocky Flats Division, Dow Chemical U.S.A., Golden, Colorado. January 7, 1974.

6. William H. Tyree and Robert W. Bistline. Plutonium-239 Detection In Vivo with a Germanium-Lithium Array. RFP-1488. Rocky Flats Division, The Dow Chemical Company, Golden, Colorado. June 12, 1970. 
RFP-2328 